\title{
Focus on psychiatry in South Africa
}

\section{ROBIN EMSLEY}

South Africa is a country of great fascination to those interested in the origins, development and behaviour of humankind. For example, recent fossil discoveries appear to confirm Darwin's hunch that Africa and perhaps southern Africa-was the cradle of humankind. Caves in the Sterkfontein Valley near Johannesburg have produced abundant scientific information on the evolution of modern man over the past 3.5 million years. This is of interest not only from a historical point of view but also in terms of modern science. With the significant advances in medical genetics in general, and psychiatric genetics in particular, there has been a growing interest in homogeneous populations with novel gene pools. South Africa is a rich source of homogeneous populations with an apparently common ancestry.

The more recent history of South Africa provides reminders of the darker side of human nature. The apartheid era was universally condemned as one of the worst examples of human rights violations. On a brighter note, the relatively peaceful transition to democracy and the accompanying reconciliation process has offered a message of hope to the rest of the world. Finally, the 'rainbow nation' with its cultural and ethnic diversity offers unique opportunities for investigating cultural aspects of psychiatry.

\section{HISTORY}

Institutional medical practice began in South Africa over 300 years ago with the establishment of a small hospital in Cape Town by Jan van Riebeeck. The first hospital to cater specifically for mentally deranged persons was established in 1711. It was an apartment that was added to the new Cape Hospital, which had been completed in 1699 by Simon van der Stel. The Old Somerset Hospital was the first hospital offering care for the insane from its inception in 1818. However, these facilities were regarded as inappropriate for this purpose, and in 1846 the prison colony on Robben Island was converted into a hospital for lepers, lunatics and other chronically ill patients. By 1912, the Robben Island Infirmary housed 500 mental patients. During this period, several other 'lunatic asylums' were built, ensuring that mentally ill patients were largely isolated from the community. These included the Town Hill Asylum in Pietermaritzburg, Fort England Mental Hospital in Grahamstown, Valkenberg Lunatic Asylum in Cape Town, and the Pretoria Lunatic Asylum (Makepeace, 1969).

The Mental Disorders Act was introduced in 1916. No provision was made for neurotic and personality disorders, alcohol dependence or learning disability. When the Union of South Africa was formed in 1910, there were eight mental institutions caring for 3624 patients. In 1955 there were 13 government mental hospitals and 17881 patients. Today there are 24 registered public psychiatric hospitals, accommodating some 14000 acute and long-term care patients.

\section{SERVICES}

Psychiatric services in South Africa have, along with all other medical services, been in a process of transformation since the democratisation of the country in 1994. Services were previously fragmented along racial lines. They were also concentrated in urban areas and overwhelmingly hospitalbased. Pockets of academic excellence in the larger cities were surrounded by vast expanses of rudimentary services in the rural areas. The non-academic publichospital services were largely custodial and the human rights of patients were often disregarded. Even health care personnel were guilty of discriminating against and stigmatising psychiatric patients (Gagiano, 1995).
The present move is towards establishing community-based services, with the integration of mental health services into primary health care.

The stated aim of the national Department of Health is to provide accessible, equitable, adequate and appropriate mental health services. This is seen not only as a political imperative, but also a moral right (Freeman, 1998). However, the process has been hamstrung by budgetary constraints. Transformation to a more comprehensive mental health approach including prevention and promotion, as well as extending services beyond those for the severely mentally ill, has to be accomplished within the available resource pool. The integration of mental health into primary health care services is lagging behind. Primary health care workers have to deal with huge clinical loads, and their training in mental health is often inadequate. Patients with psychiatric disorders are not being identified and treated. Psychiatric hospitals are still frequently acting as first-line facilities, particularly for disruptive patients and those with psychosis.

Psychiatric services are poorly developed in rural areas. The diagnostic profile of patients seen in these areas reflects some of the problems encountered. The most common diagnostic groups of patients attending the ambulatory psychiatric services in a rural area were epilepsy $(48 \%)$ and schizophrenia $(22 \%)$. There were very few patients diagnosed with mood disorders (4\%) and none with anxiety disorders (Lee et al, 1995). The management of epilepsy by psychiatric services is common to most African countries, possibly because of the scarcity of neurologists and the frequency of psychiatric comorbidity in these patients. Learning disability is another area in which services are vestigial, particularly for the mildly to moderately disabled. The virtual absence of 'soft psychiatry' indicates that many people with anxiety, mood and other non-psychotic disorders are either not seeking help, or are making use of alternative therapies such as those of traditional healers. It would appear that large numbers of subjects with psychiatric disorders consult traditional healers, who often seem to fulfil the role of psychotherapist (Behr \& Allwood, 1995).

The emphasis in the past has been on caring for the severely mentally ill. Concerted efforts are being made to assist with preventive and promotive aspects of mental health, and providing adequate services to deal with 
psychiatric patients other than the severely mentally ill. Child and adolescent services are severely under-resourced. Other specialised services, such as old age psychiatry and neuropsychiatry, have dedicated staff and facilities at only a few centres.

\section{PERSONNEL}

South Africa has a population of approximately 44 million. There are 429 registered psychiatrists. It is not known exactly how many are currently practising in the country, although a recent survey indicated that $73 \%$ of registered psychiatrists were doing so (Flisher et al, 1997). The majority of the others were practising overseas, and some were retired. South Africa has approximately one registered psychiatrist per 100000 inhabitants. Although this compares favourably with countries such as India (one per 420000 ) (Freeman, 1998), South African psychiatrists are not distributed evenly throughout the country. By far the majority are concentrated in the Cape Town and Gauteng (JohannesburgPretoria) regions. Also, $56 \%$ are in private practice. Private practice psychiatry provides first-world standards of care for the approximately $20 \%$ of the population who can afford to pay for it - the majority of whom are funded by medical insurance. (Managed health care has become a significant role-player, with limits increasingly being placed on treatment options and durations.) The other $80 \%$ rely on public services. Even within the public services, psychiatrists are concentrated in certain areas. Thus, although there are 167 psychiatrists in state hospitals, only $4.7 \%$ work exclusively in a rural setting. The North-West Province has no full-time state psychiatrist, and Northern Cape and Mpumalanga have only one each.

Psychiatrists have to deal with large clinical loads. Those working in academic settings reported working 49.5 hours per week, and those in private practice 48.8 hours per week. The academic psychiatrists spent only 5.7 hours per week on research, and 7.6 hours per week teaching (Flisher et al, 1997). Compared with European standards, psychiatrists in South Africa are poorly paid. For example, a senior psychiatrist in full-time hospital practice (academic and non-academic) earns SA Rands 243440 ( $£ 23634$ ) per annum. A form of limited private practice, referred to as RWOPS (remunerative work outside the public sector), is permitted. This has to take place outside of normal working hours, and away from the workplace. The income of psychiatrists in private practice is considerably greater than that of those in full-time hospital practice.

Generally speaking, psychiatrists in South Africa are more biologically oriented than those in the UK. Psychotherapeutic approaches are predominantly cognitivebehavioural. In the state sector, the emphasis is on the treatment of the severely mentally ill, so that psychopharmacology is the major form of treatment applied. In private practice, psychiatrists often work in conjunction with clinical psychologists. Because of large clinical loads, patients requiring anything more than supportive psychotherapy may be referred to the clinical psychologist. However, there are psychiatrists with a particular interest in psychotherapy, often psychodynamic psychotherapy. Indeed, there is a thriving Jungian school of analytical psychotherapy in Cape Town.

There are clearly too few psychiatrists in South Africa. On the one hand, not enough are being trained; on the other, many opt to leave the country, often shortly after qualifying. Although statistics are not available, the number of those who have emigrated over the past few decades is enormous. Reasons most commonly given for leaving include uncertainties regarding the future of academic psychiatry and private practice, financial considerations, socio-political insecurities, and concerns about violence and crime. There is a worldwide shortage of psychiatrists, and recruiting agencies are very active. Advertisements appear frequently and regularly in medical journals and through the mail. Attractive salaries and work conditions are offered, together with relocation assistance. A substantial proportion of psychiatrists recruited to English-speaking countries such as the UK, Australia, New Zealand and Canada are from South Africa.

\section{TRAINING}

\section{Postgraduate training}

The standard of postgraduate psychiatry training in South Africa has traditionally been good, and has enjoyed international recognition. Considerable effort has been made to ensure the maintenance of high standards. University departments are responsible for specialist training. There are two routes for an individual to qualify and register as a psychiatrist. One is to complete a master's degree in psychiatry - MMed(Psych) - through a university, and the other is to complete the fellowship of the College of Psychiatrists (Colleges of Medicine of South Africa) FCPsych. There is now a strong move towards establishing a single national qualifying examination, and the regulations and curriculum of the FCPsych are currently being reviewed in order to make it acceptable by all universities for this purpose. Both the MMed(Psych) and FCPsych degrees require a 4-year full-time training period in an approved registrar post. Candidates for registrar posts must have obtained the MBChB degree and completed a 1-year housemanship, plus 1 additional year as a medical practitioner. Both the MMed and FCPsych courses comprise Part I examinations concentrating on the neurosciences and psychology, and Part II examinations comprising general and special psychiatry and neurology. The MMed(Psych) degree requires in addition a thesis. We are in a fortunate position insofar as psychiatry is regarded as a popular speciality among many young doctors, so that waiting lists for registrar posts are the rule at most universities. This means that high-calibre candidates continue to enter the system. There are now eight medical schools in the country, with approximately 130 registrar posts in total. Child and adolescent psychiatry is the only recognised subspeciality within psychiatry, with 2 years' additional supervised training.

One major problem is that not enough Black doctors have been attracted to psychiatry. This was recognised as the single most urgent need for the effective development of psychiatric services in South Africa as far back as 1969 (Makepeace, 1969). Although considerably more have been taking up psychiatry registrar posts recently, there are still far too few. Only $10.8 \%$ of South African psychiatrists are able to communicate fluently in one or more African language (Flisher et al, 1997). Part of the problem is that still relatively few Black doctors are qualifying, although the racial profile of medical students is steadily moving closer to that of the general population.

\section{Undergraduate training}

We are fortunate in that the national regulatory body, the Health Professions Council of South Africa, has recognised Psychiatry 
as the fifth major clinical speciality, together with Medicine, Surgery, Paediatrics, and Obstetrics and Gynaecology. This ensures that adequate training time is allocated to psychiatry, including a compulsory clinical rotation in the 6th year of $\mathrm{MBChB}$ training. This exposure is probably one of the reasons why psychiatry is a popular speciality. Most medical schools, in spite of staff shortages, provide good undergraduate teaching courses in psychiatry.

\section{RESEARCH}

Research in psychiatry has historically been neglected in South Africa. Academic departments of psychiatry were traditionally service-oriented, sometimes even regarding research as a luxury that should be left to psychiatrists in more affluent countries. In the past, the Medical Research Council of South Africa allocated a pitifully small portion of its budget to psychiatry and mental health. Unlike the other medical specialities, no academic staff are on university establishments, and research fellowships were, until recently, almost non-existent. With a few notable exceptions, research was fragmented and mostly conducted in isolation. However, recently things have changed. There is an increased awareness of the relevance of mental health services in the delivery of comprehensive health care. The National Health Plan has highlighted mental health and substance misuse priority areas for development. Likewise, the Medical Research Council has recognised mental health and substance misuse as research priorities, and funding is more forthcoming. Strong preference is given to supporting projects of specific relevance to South Africa, as well as to those incorporating capacity development - particularly of previously disadvantaged institutions and individuals.

There has been a thorough rethinking of the directions of our research. Clearly, epidemiological studies are a prerequisite for planning appropriate services. Clinical research, around which specialised services can be developed, is just as important. Specific areas have been highlighted, for example, the psychiatric aspects of human immunodeficiency virus (HIV), and the causes and emotional consequences of trauma on individuals and communities. Psychopharmacology research is important in a country where a large portion of the public psychiatric services deals with management of the severely mentally ill, and where conventional psychotherapeutic approaches are limited not only by small numbers of psychotherapists but also by communication difficulties (there are 11 official languages in South Africa) and cultural considerations. The cultural diversity of South Africa renders it very suitable for research into cultural aspects of psychiatry. Also, research into the role of traditional healers and alternative medicines is called for. Very little research has been conducted concerning the efficacy and safety of traditional healing, and the available studies are described largely in anthropological and psychological terms (Behr \& Allwood, 1995).

A recent review of research publications by South African authors (Fourie et al, 2001) found that research output has been increasing. Fifty-six per cent of all Medline-listed articles in the field of psychiatry in South Africa over the past 31 years were published in the past 7 years. However, in the majority of cases $(51 \%)$ the authors were from medical departments other than psychiatry. The paucity of collaborative research is reflected in the high percentage of single-author publications (40\%). Also, relatively few authors wrote more than one paper, suggesting insufficient development and maintenance of research skills. Many of the articles were reviews (25\%), or epidemiological surveys $(19 \%)$. There has been a lack of work on children, adolescents, learning disability, the elderly and gender-specific issues. Specific diagnostic areas requiring future attention include the HIV epidemic, substance misuse and post-traumatic stress disorder. There is no nationwide epidemiological survey of psychiatric disorders in South Africa.

This country offers many opportunities for international collaborative research. There is a great need for large, welldesigned studies in fields such as epidemiology, diagnosis, genetics, psychotherapy and psychopharmacology.

\section{PSYCHIATRY AND APARTHEID}

Just a decade ago we were living and working in an oppressive and discriminatory system. As part of the national policy, health services were fragmented along racial lines. At one stage there were 14 health ministries! A few psychiatrists were involved in the planning and implementation of segregated services, and considerably more defended them. The majority of psychiatrists, however, were gravely concerned and voiced their opposition, although, in retrospect, not loudly enough (Allwood, 1997). The professional body for psychiatrists, the Society of Psychiatrists of South Africa, made numerous statements and protests at the time. Some members were more vociferous in their opposition than others, and we were not always united in our anti-apartheid stand.

Of all the medical specialities, psychiatry - the most influenced by the prevailing social and political climate - was the most criticised by the international community. Psychiatric services were inspected by overseas groups and condemned. In 1978 the American Psychiatric Association compiled a report after a committee of leading American psychiatrists inspected psychiatric facilities in South Africa. They found that psychiatric care for Black people was grossly inferior to that for White people, that unacceptable medical practices had resulted in needless deaths of Black patients, and that "apartheid has a destructive impact on the families, social institutions, and the mental health of black South Africans" (American Psychiatric Association, 1983). A Special Committee on the Political Abuse of Psychiatry of the Royal College of Psychiatrists investigated the matter and found substantial evidence of racial discrimination in the provision of psychiatric services (Royal College of Psychiatrists, 1983).

Concern was expressed regarding the Royal College of Psychiatrists' continued silence on the political abuses of psychiatry in South Africa (Sashidharan et al, 1982). In 1984, a call went out to the World Psychiatric Association to expel the "racist Society of Psychiatrists of South Africa" because of its collusion with apartheid (Jewkes, 1984). In 1987, a resolution was approved by the Royal College of Psychiatrists condemning racism and urging College members to support the Commonwealth Nassau Accord of October 1985, which recommended discouragement of participation in cultural and scientific events except where these contributed towards the ending of apartheid or had no possible role in promoting it (Birley, 1988).

Academic boycotts and international isolation followed. Psychiatrists continued to be accused of colluding with the apartheid government. Again, this was true in some cases. However, other psychiatrists were frequently able to desegregate facilities 
unofficially long before statutory changes took place.

\section{TRUTH AND RECONCILIATION COMMISSION}

In response to the gross violations of human rights in the past, the post-apartheid government established a Truth and Reconciliation Commission (TRC) in a move to promote national unity and reconciliation. The intention was to establish as far as possible the nature, causes and extent of gross human rights violations by granting amnesty to perpetrators who made full disclosures and by affording victims the opportunity to give accounts of their sufferings. For the nation as a whole, the TRC has had a positive, and perhaps even therapeutic effect. There are a number of issues regarding the TRC that are of relevance to psychiatry. Both perpetrators and victims recounted almost unbelievable incidents of extreme emotional trauma. Mental health professionals provided advice regarding the manner in which testimony should be taken, and provided psychological support when necessary to those who testified. TRC staff members were trained in issues relevant to psychological support, and some of the TRC commissioners were mental health professionals (Stein, 1998).

\section{THE SOCIETY OF PSYCHIATRISTS OF SOUTH AFRICA}

The Society of Psychiatrists of South Africa (SPSA) is the representative body for psychiatrists. It is affiliated to the South African Medical Association, and membership is voluntary. During the apartheid years, the SPSA was severely criticised for failing to challenge the South African government regarding abuses in mental health.

These days, the SPSA is an active and well-organised body looking after the interests of psychiatrists and their patients. The executive committee deals with various issues such as ethics, human rights, standards of practice, private practice fees and destigmatisation of psychiatry. Members are kept informed by means of regular newsletters and a journal. The South African Journal of Psychiatry was established in 1995, and publishes four issues per year. Considerable time is spent on dealing with controversial matters. For example, a recent strong lobby for prescription rights for psychologists required vigorous intervention. The SPSA issued a statement warning of the grave risks to patient care, and met with government authorities on the matter.

Also, scientologists (in the guise of the 'Citizens Commission for Human Rights') are active and vociferous in South Africa, and have recently been granted official recognition. Even a few doctors are members! Their frequent anti-psychiatry campaigns demand substantial attention from the SPSA. Occasionally they focus on issues of real concern, and then claim credit for having brought about changes. So-called 'sleep therapy' is one such issue. This dubious procedure is still being used in South Africa, largely by general practitioners (and a few psychiatrists) in private practice. $\mathrm{Pa}$ tients with various emotional problems are hospitalised and heavily sedated, although not in the original form of administration of high-dose barbiturates. Because the practice has been associated with a number of deaths, the SPSA issued a statement in the South African Medical Journal condemning the practice and warning that it could be construed as medical malpractice.

\section{RELATIONSHIP BETWEEN THE SOCIETY OF PSYCHIATRISTS OF SOUTH AFRICA AND THE ROYAL COLLEGE OF PSYCHIATRISTS}

Historically, there have been close ties between psychiatrists in South Africa and in the UK. However, particularly during the 1980s, relationships between the SPSA and all international psychiatry organisations, including the Royal College of Psychiatrists, were strained. Since the political normalisation of South Africa, important strides have once again been made in fostering good relations.

In 1990 a delegation of psychiatrists from the Royal College, under the chairmanship of Dr Fiona Caldicott, paid a visit to South Africa. This was at the start of the political transition, 2 weeks after the release of Nelson Mandela. The group stressed that they were here to offer assistance rather than to inspect, and tabled a report that encouraged outside support (Royal College of Psychiatrists, 1990). Since then, representatives of the SPSA regularly attend the Royal College's meetings, and visits of Royal College representatives to South Africa have taken place. In 1997 Professor Andrew Sims, an ex-president of the Royal College of Psychiatrists, and in 2000 Professor John Cox, current president, visited our country. In addition to touring the academic centres and lecturing extensively, productive meetings with SPSA representatives took place on matters such as teaching and examining, research collaboration, continuing professional development and ethical issues. Professors Sims and Cox were both awarded Honorary Fellowships of the Colleges of Medicine of South Africa.

\section{SOME FUTURE CHALLENGES}

One of the major challenges facing psychiatry in South Africa (and all other emerging economies) is to find ways of incorporating technological advances into public services. Clinical psychiatry has become increasingly reliant upon these new developments that have improved patient care but, at the same time, have made psychiatry more expensive to practise. Consequently, the gap in the standard of care between high-income and low-income countries is widening (Sartorius \& Emsley, 2000). For example, brain-imaging techniques have become an important tool in ruling out intracranial pathology, establishing a diagnosis and predicting treatment outcome. Although computerised tomography, magnetic resonance imaging and single photon emission tomography facilities are available in some urban areas, the majority are in the private sector. Those in public hospitals are frequently overloaded and access to them is limited. Also, new psychopharmacological agents offer improved efficacy and/or safety profiles for the treatment of anxiety, mood, psychotic and other disorders. The acquisition costs of these drugs are considerably greater than those of their predecessors, so that their availability in the public sector is very limited. Policymakers remain unconvinced of the benefits of these new developments, and argue (correctly) that health-economics studies conducted in Europe and North America cannot be generalised to South Africa. Such studies are urgently needed in lower-income countries. Whereas in the past psychiatry was able to provide reasonable services on a very low budget, we now need to compete with the other medical specialities for a 
more appropriate portion of the health budget.

In planning future services, cognisance needs to be taken of the demographic changes that are taking place, and the impact that these changes will have on psychiatry. For example, the age of populations in developing countries is steadily in creasing, and age-related disorders such as the dementias are likely to become far more prevalent. However, at the same time, the HIV epidemic has become the major health threat in sub-Saharan Africa. The statistics are staggering-according to the World Health Organization there were 34.3 million people worldwide estimated to be living with HIV/AIDS at the end of 1999 , of whom 24.5 million $(71 \%)$ are in sub-Saharan Africa. Of the estimated 2.8 million deaths worldwide from HIV/ AIDS, 2.2 million $(79 \%)$ were in subSaharan Africa. The cumulative number of children estimated to have been orphaned by AIDS at age 14 or younger at the end of 1999 is 13.1 million worldwide, of whom 12.1 million are in sub-Saharan Africa (UNAIDS, 2000). Mental health issues related to HIV threaten to overwhelm available resources. Effective and affordable strategies need to be developed to deal with these challenges.

More psychiatrists are needed in the public services, particularly in rural areas. The ongoing emigration of psychiatrists and the shortage of Black psychiatrists need urgently to be addressed.

\section{CONCLUSION}

Land of milk and honey? Clearly not. Land of opportunity? Most definitely. For psychiatrists like myself it is a great experience to be part of the transition from the old to the new; to be witness to a most remarkable change - from an abominable, oppressive system to democracy; to be a part of the building of accessible, equitable, adequate and appropriate mental health services for the new South Africa.

\section{ACKNOWLEDGEMENTS}

I am grateful to Professor Cliff Allwood and Dr Sue Hawkridge for their helpful advice and comments on a draft of the manuscript.

\section{REFERENCES}

Allwood, C.W. (1997) Psychiatry in South Africa yesterday, today and tomorrow. South African Medical Journal, 87, 1728-1732.

American Psychiatric Association (1979) Report of the Committee to visit South Africa. American Journal of Psychiatry, 136, 1498.

Behr, G. M. \& Allwood, C. W. (1995) Differences between Western and African models of psychiatric illness. South African Medical Journal, 85, 580-584.

Birley, J. L.T. (1988) South African psychiatrists and the Royal College of Psychiatrists. New England Journal of Medicine, 319, |413-14|4.

Flisher, A. J., Riccitelli, G., Jhetam, N., et al (1997) A survey of professional activities of psychiatrists in South Africa. Psychiatric Services, 48, 707-709.

Fourie, J., Flisher, A., Emsley, R. A., et al (2001) Psychiatric research in South Africa: A systematic review of Medline publications. South African Journal of Psychiatry, in press.

Freeman, M. (1998) Mental health service change. South African Medical Journal, 88, 742-744.

Gagiano, C. A. (1995) A psychiatric service at primary care level. South African Medical Journal, 85, 568.

Jewkes, R. (1984) The Case for South Africa's Expulsion from International Psychiatry. New York: UN Centre Against Apartheid.

Lee, T., Price, M. \& Allwood, C.W. (1995) The outpatient care of psychiatric patients in a rural area: Mhala district, Northern Transvaal. South African Medical Journal, 85, 57I-577.

Makepeace, R. (1969) The history of psychiatry in South Africa. Canadian Psychiatric Association Journal, 14, 221-222.

Royal College of Psychiatrists (1983) Report of the Special (Political Abuse of Psychiatry) Committee on South Africa. Bulletin of the Royal College of Psychiatrists, 7, 115 .

- (1990) Report on the College's Preliminary Visit to South Africa. Council Report CRII. London: Royal College of Psychiatrists.

Sartorius, N., Emsley, R. A. (2000) Psychiatry and technological advances: implications for developing countries. Lancet, 356, 2090-2092.

Sashidharan, S. P., Cox, J. L., Orley, J., et al (1982)

South Africa and the Royal College of Psychiatrists. Lancet, ii, 497-498.

Stein, D. J. (1998) Psychiatric aspects of the Truth and Reconciliation Commission of South Africa. British Journal of Psychiatry, I73, 455-457.

UNAIDS (2000) Report on the Global HIVIAIDS Epidemic. Geneva: Joint United Nations Programme on HIVIAIDS.

Robin Emsley Head, Department of Psychiatry, University of Stellenbosch, PO Box 19063, Tygerberg 7505, Cape Town, South Africa 